\title{
A Stability Indicating UV-HPLC Method for the Determination of Potential Impurities in Nandrolone Phenylpropionate Active pharmaceutical ingredient
}

\author{
Amber BHARTI*, Christine JEYASEELAN. \\ Department of chemistry, Amity Institute of Applied Sciences, Amity University, Uttar Pradesh, Noida 201303, India.
}

\begin{abstract}
A reverse phase stability indicating HPLC method has been developed for the identification and quantification of potential impurities in Nandrolone phenylpropionate active pharmaceutical ingredient. The chromatographic separation of potential impurities was achieved in Inertsil ODS-3Vcolumn (250 mm x $4.6 \mathrm{~mm}, 5 \mu \mathrm{m}$ ) using gradient elution method. Mobile phase-A was prepared using $0.1 \%$ orthophosphoric acid in water and methanol mixture in a ratio of (90:10, v/v) and mobile phase-B was only acetonitrile. The developed method was validated as per the ICH guidelines for specificity, linearity, precision and accuracy. Specificity of the method was confirmed by peak purity analysis using photodiode array (PDA) detector. The value of correlation coefficient was greater than 0.999 for Nandrolone phenylpropionate and its six impurities. Accuracy of the method was established between $93.3 \%$ to $109.0 \%$ for all impurities. Nandrolone was found to be the major degradation impurity. The proposed method is suitable for routine as well as stability studies.
\end{abstract}

Keywords: Nandrolone phenylpropionate, nandrolone, anabolic, steroid.

\section{INTRODUCTION}

Nandrolone phenylpropionate (NPP) is known as 19-noretestorone $\beta$-phenyl propionate $^{1}$. It is an anabolic-androgenic steroid. It is a fast-acting ester derivative form of Nandrolone and has strong anabolic effect with weak androgenic

Corresponding author:

Department of chemistry, Amity Institute of Applied Sciences, Amity University, Uttar Pradesh, Noida 201303, India.

Telephone number: $+91-9953110546$

Email address: bharti_amber@rediffmail.com

ORCIDs

Amber Bharti, 0000-0001-8879-3620.

Christine Jeyaseelan, 0000-0001-7386-2195.

(Received 26November 2019, accepted 11November 2020) 
effect. NPP is injected intramuscularly every once in a week for 12 weeks and the dose may vary from $25 \mathrm{mg} / \mathrm{mL}$ to $50 \mathrm{mg} / \mathrm{mL}$ of steroid dissolves in oily formulation $^{2}$. Nandrolone Esters have been used in the treatment of osteoporosis, anemia, increase in muscle mass, to induce protein synthesis in skeletal muscles and improve respiratory muscle functions in COPD (Chronic Obstructive Pulmonary Disease $)^{3-7}$. The effect of NPP in rats has been reported by Hale $(1972)^{8}$.

The related substances method by TLC and assay method by UV spectrophotometer have been reported in Indian Pharmacopoeia and United States Pharmacopoeia respectively ${ }^{9,10}$. The work on the development and validation of multi-residue method for the detection of wide range of hormonal anabolic compounds in hair using gas-chromatography-tandem mass spectrometry has been carried out ${ }^{11}$. The effect of Nandrolone esters in the growth and histology of urine and hair has been studied by Groot et $\mathrm{al}^{12}$. The validated GC-MS and UHPLC-MS method have been reported for the quantitative determination of anabolic steroids in formulation products and dietary/nutritional supplements ${ }^{13-16}$. Findings on the effect of side chain, the injection site and the injection volume on the pharmacokinetics and pharmacodynamics of Nandrolone esters in an oil vehicle in men is also available ${ }^{17}$. Various research articles have also reported for the development and analysis of Nandrolone esters ${ }^{18-21}$.

However, reverse phase HPLC method has not been reported yet for the determination of potential impurities in NPP (including major pharmacopoeias such as USP, Ph.Eur, BP, JP, and IP). Therefore, it is important to have a stability indicating method for the quantification of potential impurities in NPP which is specific and accurate. The quality, efficacy and safety are significantly affected by the impurities present in the drug product ${ }^{22}$. As per the current ICH Guideline of stability testing of drug substances, forced degradation must be carried out to establish that the method is stability indicating and the analytical methods need to be validated ${ }^{23-26}$. The current work involves method development, forced degradation and method validation for NPP.

\section{METHODOLOGY}

\section{Materials and chemicals}

NPP sample (99.7\% purity, 10 g, Batch number: NPP/oo9/005), Imp-2 (98.3\% purity, 1 g, Batch number: ND/031/016), Imp-3 (98.7\% purity, 500 mg, Batch number: BD/035/o09), Imp-4 (98.5\% purity, $500 \mathrm{mg}$, Batch number: NPP/o09/018), Imp-5 (98.9\% purity, 500 mg, Batch number: NPP/oo9/023), Imp-6 (98.1\% purity, 500 mg, Batch number: NPP/009/029) were obtained from chemical research division, Ipca laboratories Ltd. (Vadodara, India). Imp-1 
(99.0\% purity, $100 \mathrm{~g}$, Lot number: STBD4764V) was obtained from Sigma-Aldrich (Steinheim, Germany). HPLC grade water for the analysis purpose was obtained from Milli-Q plus water purification system (Millipore, Bedford, MA, USA). HPLC grade acetonitrile and methanol was purchased from Merck India (Mumbai, India).

\section{Instrumentation and HPLC conditions}

The instruments used in the study include: HPLC separation module (2695) with UV detector (2487) and photodiode array detector (2996) (Waters Corporation, Milford, MA, USA); A photostability chamber model NEC-104RTS (Newtronic, Mumbai, India).

Inertsil ODS-3V column ( $250 \mathrm{~mm} \times 4.6 \mathrm{~mm}, 5 \mu \mathrm{m}$ ) HPLC column was used in the analysis (GL Sciences). For the gradient elution method, mobile phase-A and mobile phase-B were used. Mobile phase-A was prepared using $0.1 \%$ orthophosphoric acid in water and methanol mixture in a ratio of (90:10, v/v) and mobile phase-B was only acetonitrile. The column temperature was kept at $40^{\circ} \mathrm{C}$ for the analysis; flow rate of $1.0 \mathrm{~mL} / \mathrm{min}$; injection volume was $20 \mu \mathrm{L}$; detector wavelength was fixed at $240 \mathrm{~nm}$ and $210 \mathrm{~nm}$; sample temperature was $25^{\circ} \mathrm{C}$. Diluent was a mixture of water and acetonitrile in a ratio of $(20: 80, \mathrm{v} / \mathrm{v})$. Gradient program is tabulated in Table 1.

Table 1. Linear gradient program.

\begin{tabular}{|c|c|c|}
\hline Time/minutes & Mobile phase-A, $\%$ & Mobile phase-B, $\%$ \\
\hline 0 & 45 & 55 \\
\hline 25 & 20 & 50 \\
\hline 35 & 10 & 90 \\
\hline 40 & 45 & 55 \\
\hline 50 & 45 & 55 \\
\hline
\end{tabular}

\section{Preparation of sample and stock solution for validation}

NPP test sample was prepared by transferring about $20 \mathrm{mg}$ of sample into 50 $\mathrm{mL}$ volumetric flask, added10 $\mathrm{mL}$ of acetonitrile to it and sonicated for $1.0 \mathrm{~min}$ and made uptothe volume with diluent $(400 \mu \mathrm{g} / \mathrm{mL})$.

Individual stock solution of about $800 \mu \mathrm{g} / \mathrm{mL}$ was prepared by transferring about $20 \mathrm{mg}$ each of NPP, imp-1, imp-2, imp-3, imp-4, imp-5 and imp-6 into separate $25 \mathrm{~mL}$ volumetric flasks, added $10 \mathrm{~mL}$ of acetonitrile to it and sonicated for 1.0 min and made upto the volume with diluent.From the above individual stock solution transfer 0.75 mlinto separate $20 \mathrm{~mL}$ volumetric flasks, made upto the volume with diluent and shake well. This solution was labeled as standard stock solution $(30.0 \mu \mathrm{g} / \mathrm{mL})$. Further from this standard stock solution, the desired solutions of different concentrations were prepared for validation. 


\section{Preparation of forced degradation samples}

About $20 \mathrm{mg}$ each of sample was weighed and transferred into 3 separate $50 \mathrm{~mL}$ volumetric flasks and labeled as 1, 2 and $3.10 \mathrm{~mL}$ of acetonitrile was added into each volumetric and the sample was dissolved by sonicated for $1.0 \mathrm{~min} .2 \mathrm{~mL}$ of $0.5 \mathrm{~N}$ hydrochloric acid solution, 5.0 \% hydrogen peroxide solution and 0.5 $\mathrm{N}$ sodium hydroxide was also added into each volumetric flask. The flasks were kept in a water bath at $60^{\circ} \mathrm{C}$ for $2 \mathrm{~h}$ (acid hydrolysis), $60^{\circ} \mathrm{C}$ for $6 \mathrm{~h}$ (oxidative degradation) and at room temperature for $1 \mathrm{~h}$ (base hydrolysis) respectively. The excess of acid or base in volumetric flask 1 and 3 were neutralized and made upto the mark with diluents. Corresponding blank solutions were prepared. Thermal degradation was performed on solid NPP sample at $70^{\circ} \mathrm{C}$ for $48 \mathrm{~h}$. Photolytic degradation was performed by spreading the sample on petri dish and kept in a photostability chamber model NEC-104RTS (Newtronic) to get the light intensity of 1.2 million Lux hours for white light and $200 \mathrm{Wh} / \mathrm{m}^{2}$ for ultraviolet region.

\section{RESULTS and DISCUSSION}

\section{HPLC method development}

The literature search was done to check the method availability but little information was available regarding the quantification of related impurities of NPP. Hence it was decided to initiate the reverse phase HPLC method development. The aim of the proposed method is to achieve the baseline separation between all related impurities and NPP. Structure and details of NPP and its impurities are listed in Table 2. The $\lambda_{\text {max }}$ of NPP and its potential impurities were showed in Figure 1. 
Table 2. Structure and details of NPP and its impurities.

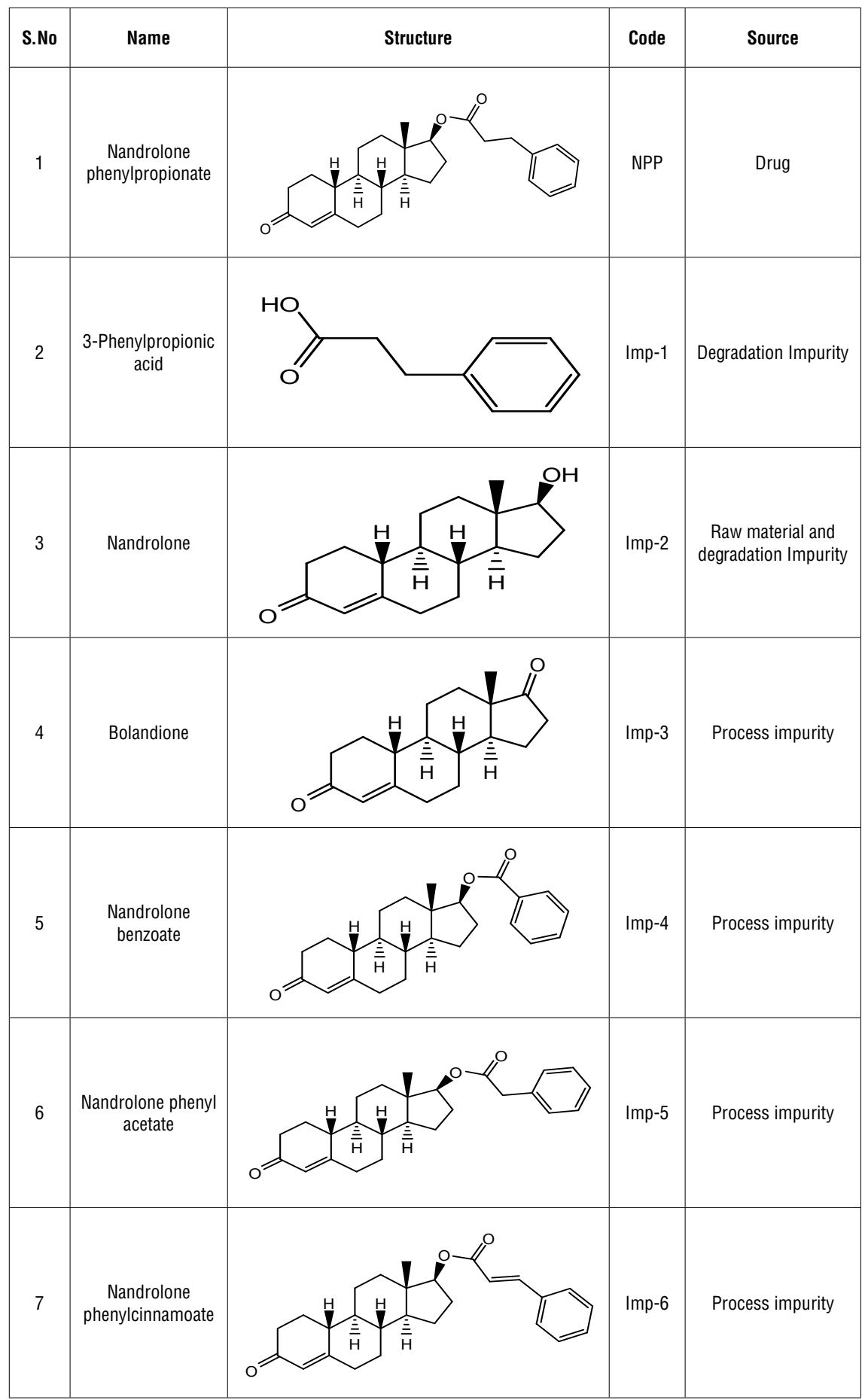




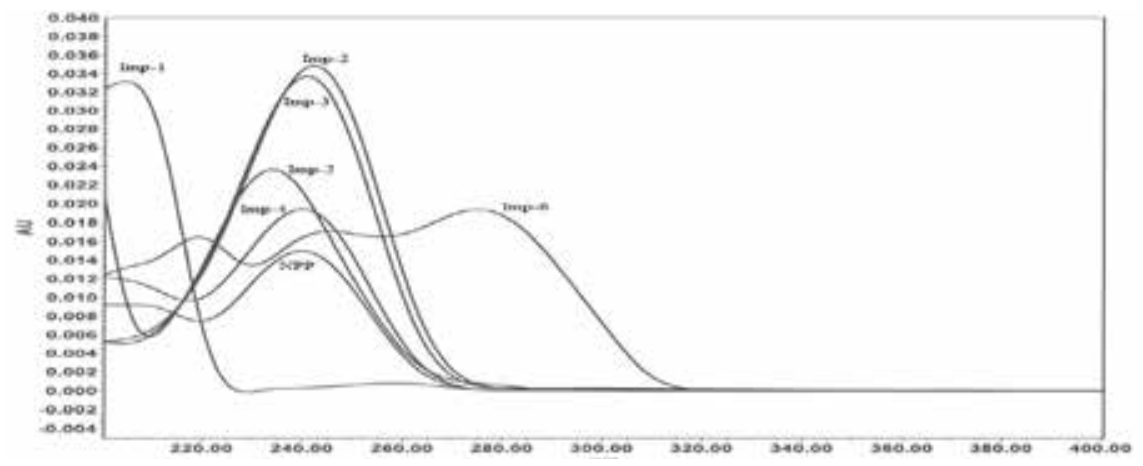

Figure 1. The $\lambda_{\text {max }}$ of NPP and its potential impurities.

The method development was initiated using water and acetonitrile as mobile phase-A and Mobile phase-B in gradient elution method, using C-8 column with dimension ( $150 \mathrm{~mm} \times 4.6 \mathrm{~mm}, 5 \mu \mathrm{m}$ ). The peak of NPP and imp- 6 co-elutes and the peak shape of imp-1 was found distorted. Finally after conducting several experiments the method was finally developed using linear gradient program. For the gradient elution method, mobile phase-A and mobile phase-B were used. Mobile phase-A was prepared using $0.1 \%$ orthophosphoric acid in water and methanol mixture in a ratio of $(90: 10, \mathrm{v} / \mathrm{v})$ and mobile phase-B was only acetonitrile. Inertsil ODS-3Vcolumn ( $250 \mathrm{~mm} \times 4.6 \mathrm{~mm}, 5 \mu \mathrm{m}$ ) was used. The column temperature was kept at $40^{\circ} \mathrm{C}$ and detector wavelength was selected as $240 \mathrm{~nm}$ and $210 \mathrm{~nm}(210 \mathrm{~nm}$ for imp-1) throughout the analysis. The NPP peak eluted at about 26 min with the base line separation of all impurities (Figure 2 and 3).

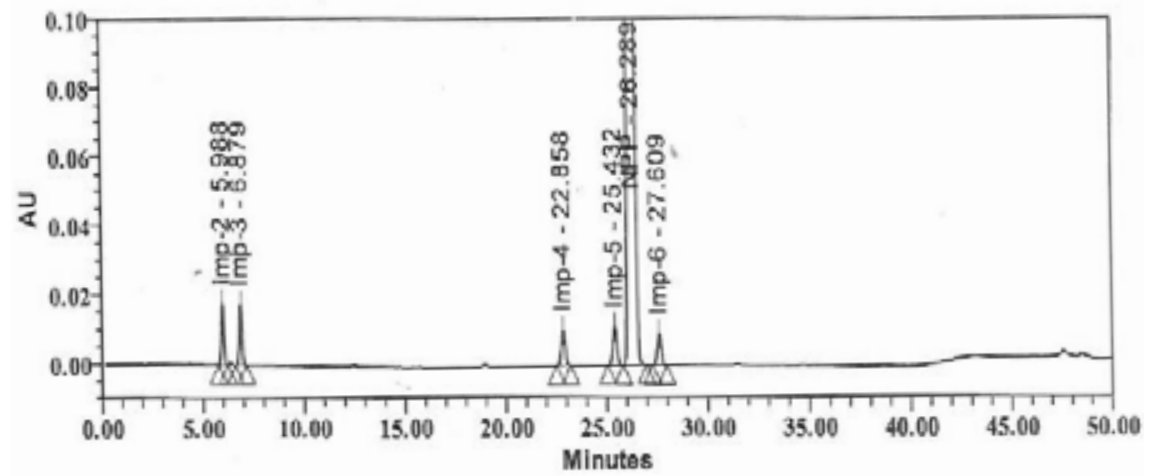

Figure 2. Chromatogram of spiked impurities in NPP at wavelength $254 \mathrm{~nm}$. 


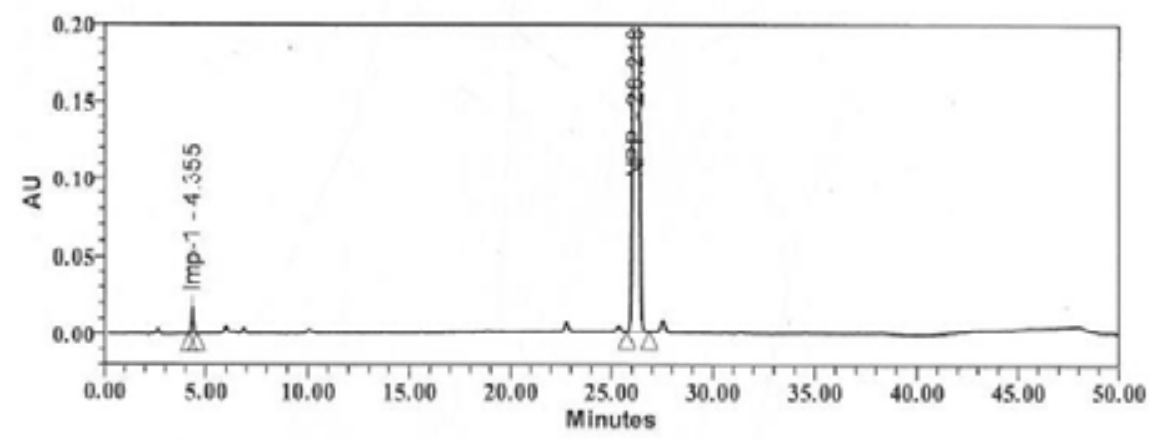

Figure 3. Chromatogram of spiked impurities in NPP at wavelength $210 \mathrm{~nm}$.

\section{Forced degradation study}

The forced degradation of NPP sample was conducted in acidic, basic, thermal, oxidative and photolytic conditions. The significant degradation of NPP was observed in acidic and basic conditions. In both the conditions, the impurity formed was identified as imp-2 at $240 \mathrm{~nm}$ and imp-1 in $210 \mathrm{~nm}$. There was no impact of oxidative, thermal and photolytic conditions on NPP. The peak purity analysis of the analyte peak obtained from PDA detector in all stress samples confirmed the spectral purity of NPP peak demonstrates the stability indicating capability of the method. The chromatograms are shown in Figure 4 and 5 and data is tabulated in Table 3.

Table 3. Percentage of degradation under different conditions using NPP sample at $400 \mu \mathrm{g} / \mathrm{mL}$.

\begin{tabular}{|c|c|c|}
\hline S No. & Condition & Degradation $\%$ \\
\hline $\mathbf{1}$ & Acidic $\left(0.5 \mathrm{~N} \mathrm{HCl}, 60^{\circ} \mathrm{C}, 2 \mathrm{~h}\right)$ & 3.5 \\
\hline $\mathbf{2}$ & Basic $(0.5 \mathrm{~N} \mathrm{NaOH}$, room temperatute, $1 \mathrm{~h})$ & 6.7 \\
\hline $\mathbf{3}$ & 0xidation $\left(5 \% \mathrm{H} 202,60^{\circ} \mathrm{C}, 6 \mathrm{~h}\right)$ & - \\
\hline $\mathbf{4}$ & Thermal $\left(70^{\circ} \mathrm{C}, 48 \mathrm{~h}\right)$ & - \\
\hline $\mathbf{5}$ & Photolytic degradation & - \\
\hline
\end{tabular}




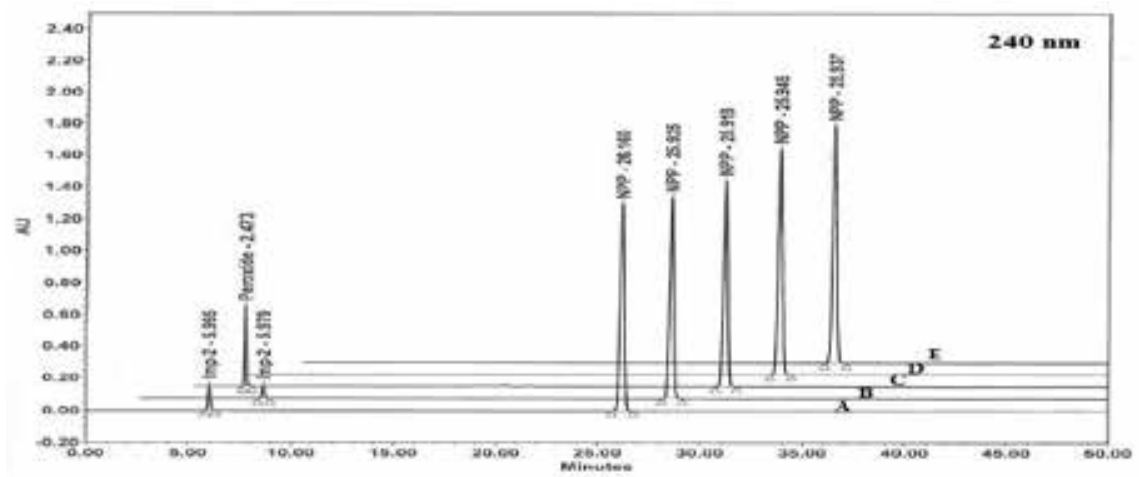

Figure 4. Chromatogram of forced degradation studies of NPP at $240 \mathrm{~nm}$ : (A) base hydrolysis, (B) acid degradation (C) oxidative degradation, (D) thermal degradation, (E) photolytic degradation.

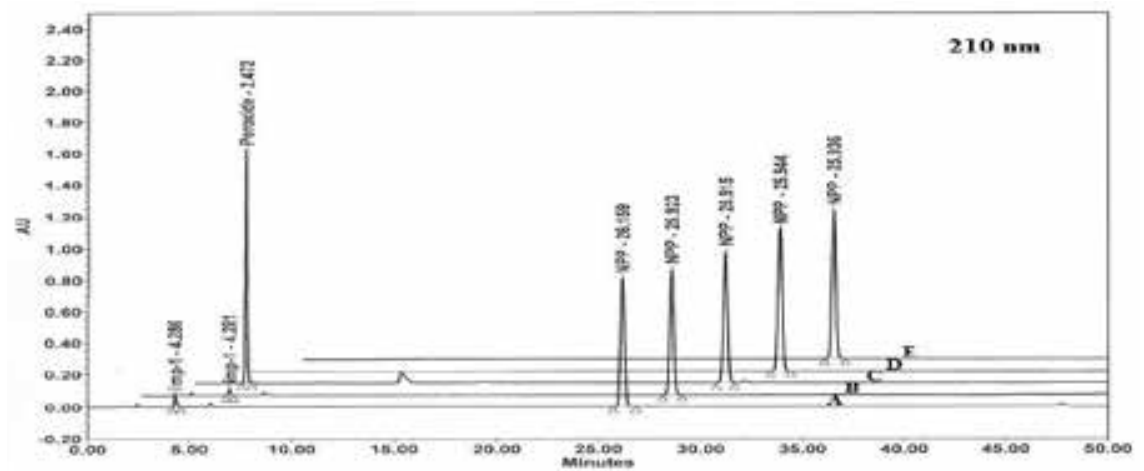

Figure 5. Chromatogram of forced degradation studies of NPP at $210 \mathrm{~nm}$ : (A) base hydrolysis, (B) acid degradation (C) oxidative degradation, (D) thermal degradation, (E) photolytic degradation.

\section{Method validation}

As per ICH guidelines the method must be validated to establish specificity, solution stability, sensitivity, linearity, precision, accuracy and robustness. The method validation was carried out for imp-1, imp-2, imp-3, imp-4, imp-5, imp6 and NPP. A summarized result of method validation is tabulated in Table 4. 
Table 4. Method Validation summary data

\begin{tabular}{|c|c|c|c|c|c|c|c|}
\hline Parameter & Imp-1 & Imp-2 & Imp-3 & Imp-4 & Imp-5 & Imp-6 & NPP \\
\hline Retention Time (RT) & 4.36 & 5.99 & 6.88 & 22.86 & 25.43 & 27.61 & 26.29 \\
\hline Relative RT & 0.17 & 0.23 & 0.26 & 0.87 & 0.97 & 1.05 & 1.00 \\
\hline Resolution & 76.00 & 3.85 & 53.85 & 6.97 & 2.27 & 3.50 & - \\
\hline Symmetry factor & 1.04 & 1.03 & 1.02 & 1.00 & 1.00 & 1.01 & 1.03 \\
\hline Response factor & 0.56 & 0.71 & 0.69 & 0.77 & 0.68 & 0.88 & 1.00 \\
\hline Linearity & 0.9998 & 0.9991 & 0.9997 & 0.9997 & 0.9993 & 0.9997 & 0.9996 \\
\hline Detection Limit $(\mu \mathrm{g} / \mathrm{mL})$ & 0.0721 & 0.0362 & 0.0364 & 0.0360 & 0.0358 & 0.0359 & 0.0361 \\
\hline Quantitation Limit $(\mu \mathrm{g} / \mathrm{mL})$ & 0.1503 & 0.1205 & 0.1212 & 0.1199 & 0.1193 & 0.1195 & 0.1202 \\
\hline $\begin{array}{l}\text { Intra-day precision } \\
(\mathrm{n}=6, \% \mathrm{RSD})\end{array}$ & 1.95 & 0.47 & 0.57 & 1.14 & 0.60 & 0.83 & -- \\
\hline $\begin{array}{l}\text { Inter-day precision } \\
(\mathrm{n}=6, \% \mathrm{RSD})\end{array}$ & 0.92 & 0.66 & 1.32 & 1.57 & 1.48 & 1.70 & - \\
\hline Accuracy at $L O Q(n=3, \%)$ & 94.6 & 106.7 & 103.3 & 104.4 & 108.0 & 93.3 & -- \\
\hline Accuracy at $100(n=3, \%)$ & 102.7 & 108.1 & 107.8 & 105.9 & 105.9 & 105.9 & -- \\
\hline Accuracy at $150(n=3, \%)$ & 103.9 & 106.3 & 109.0 & 106.0 & 105.4 & 104.5 & -- \\
\hline
\end{tabular}

\section{Specificity}

Specificity is the ability of chromatographic method to separate the analyte peak from blank interference, impurities and degradants. Specificity was done by injecting blank, NPP sample and NPP sample Co-spiked with impurities. The NPP peak was found well resolved from all six impurities and no blank interference was observed. Forced degradation study was also performed to demonstrate method specificity as well as stability indicating capability of the proposed method.

\section{Solution stability}

Stability of solutions was established by injecting spiked and unspiked sample solution kept in HPLC vial at $25^{\circ} \mathrm{C}$ in auto sampler. Area of each impurity was checked after $24 \mathrm{hrs}$ against initial (o h) and the \% difference was found less than $10 \%$, hence sample solution are stable for $24 \mathrm{~h}$ at $25^{\circ} \mathrm{C}$.

\section{Limit of detection and quantitation (Sensitivity)}

The detection Limit (LOD) and Quantitation limit (LOQ) determines the sensitivity of the proposed method. The LOD for each impurity (imp-1, imp-2, imp-3, imp-4, imp-5 and imp-6) and NPP were calculated and found to be in the range of $0.0358 \mu \mathrm{g} / \mathrm{mL}$ to $0.0721 \mu \mathrm{g} / \mathrm{mL}$. The LOQ for each impurity (imp-1, imp-2, imp-3, imp-4, imp-5 and imp-6) and NPP were calculated and found to be in the range of $0.1193 \mu \mathrm{g} / \mathrm{mL}$ to $0.1503 \mu \mathrm{g} / \mathrm{mL}$. 


\section{Linearity and range}

Linearity determines the ability of the analytical method to get the test results that are directly proportional to the analyte concentration within the given range. The solutions were prepared at six different concentration levels for all specified impurities and sample from LOQ level to $150 \%$ of impurity limit [0.15\% of the drug concentration $(400 \mu \mathrm{g} / \mathrm{mL})$. The result of correlation coefficient obtained for all analyte were found to be greater than 0.999, confirms positive correlation between peak area and concentration of impurities and NPP peak (Figure 6).

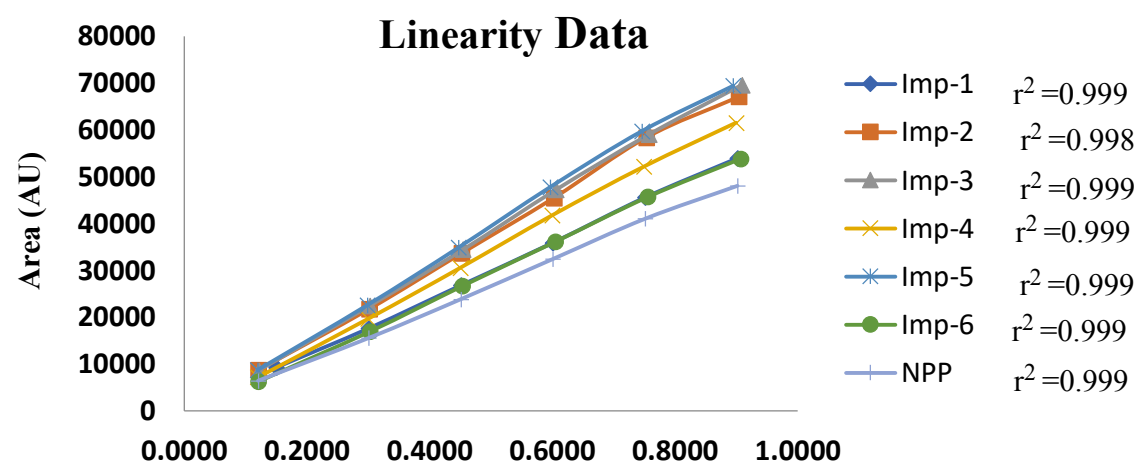

Conc. $(\mu \mathrm{g} / \mathrm{mL})$

Figure 6. Linearity data of all 6-impurities and NPP.

\section{Accuracy}

The accuracy of the method was expressed in the term of percentage recovery. The accuracy of the present method was performed at LOQ level, $100 \%$ level (0.15\% of the drug substances) and $150 \%$ level (0.225\% of the drug substances). The experiment was performed in triplicate. The percentage recovery of all impurities ranged between $93.3 \%$ to $109.0 \%$ indicating the accuracy of the method.

\section{Precision}

The precision (Intra-day precision) of the method was evaluated by preparing six individual preparations of NPP sample and spiked with $0.15 \%(0.6 \mu \mathrm{g} / \mathrm{mL})$ of each impurity with respect to sample concentration $(400 \mu \mathrm{g} / \mathrm{mL})$. Peak area of each impurity was checked and percentage relative standard deviation was calculated and found less than $2.0 \%$ for each impurity. 
The precision (inter-day precision) was also determined by performing the same procedure in same lab by different analyst on different instrument and on different dates. The percentage RSD for each impurity was found below $2.0 \%$ in both the precision indicated the good precision of the proposed method.

\section{Robustness}

The robustness of the analytical method was checked by evaluating the influence of small deliberate modifications in the HPLC method parameter. The studies showed that there was no impact on the method even by deliberately changing the chromatographic parameters (i.e. column temperature, flow rate and mobile phase composition). It was observed that the resolution among all the impurities and NPP peak was higher than 2.0. This showed the reliability of the method during routine usage of the method.

The proposed method was found to be better and advantageous over previous reported methods for quantification of potential impurities as compared to the TLC and UV spectrophotometer method describes in Indian pharmacopoeia and United States Pharmacopoeia respectively. The proposed method has been validated as per the current ICH guidelines and easy to use for routine analysis as well as stability studies.

\section{ACKNOWLEDGEMENTS}

The authors are thankful to the management of Ipca laboratories and Amity University for providing the necessary support. 


\section{REFERENCES}

1. O'Neil MJ. The Merck Index: An Encyclopedia of Chemicals, Drugs, and Biological, 15th ed. Merck\& Co.,Inc.,Whitehouse station: New Jersey; 2013. 1702 p.

2. Llewellyn W. Anabolics.10th ed. Molecular Nutrition: Jupiter, Florida; 2011. 460-467p.

3. Wijnhoven H, Ennen L, Rodenburg R, Dekhuijzen PNR. Mitochondrial Function in Diaphragm of Emphysematous Hamsters after treatment with nandrolone. Int $\mathrm{J}$ Chron Obstruct Pulmon Dis. 2oo6; 1(1): 83-89.

4. Haupt HA, Rovere GD. Anabolic steroids: A Review of a Literature. Am J Sports Med. 1984; 12:469-484.

5. Choo JJ, Emery PW, Rothwell NJ. Dose-Dependent Effect of an Anabolic Steroid, Nandrolonephenylpropionate (Durabolin), on Body Composition and Muscle Protein Metabolism in Female Rats. Ann Nutr Metab. 1991; 35: 141-147.

6. Snow DH, Munro CD, Nimmo MA. Effect of Nandrolone Phenylpropionate in the Horse: (1) Resting Animal. Equine Vet J. 1982; 14:219-223.

7.Bagchus WM, Smeets JMW, Verheul HAM, DeJager-Van DerVeen SM, Port A, Geurts TBP. Pharmacokinetic Evaluation of Three Different Intramuscular Dose of Nandrolone Decanoate: Analysis of Serum and Urine Samples in Healthy Men. J Clin Endocrinol Metab. 2005; 90: 2624-2630.

8. Hale DH. The Effect of Orchidectomy and Administration of Testosterone Propionate or Nandrolone Phenylpropionate to Orchidectomised Rats on their growth and carcass composition. $S$ Afr J Anim Sci. 1973; 1: 39-44.

9. Indian pharmacopoeia, Government of India, Ministry of Health and Family Welfare. 8th ed.; 2018. Indian Pharmacopoeia Commission: Ghaziabad; pp 2692.

10. The United States Pharmacopoeia (USP) and the National Formulary (NF). USP 40- NF

35. Rockville, Md. 2017; pp 5278-5279.

11. Rambaud L, Monteau F, Deceuninck Y, Bichon E, Andre F, Bizec BL. Development and Validation of a Multi-Residue Method for the Detection of a Wide Range of Hormonal Anabolic Compounds in Hair Using Gas Chromatography-Tandem Mass Spectrometry. Anal Chim Acta. 2007; 586: 93-104.

12. Groot MJ, Lasaroms JJP, Vanbennekom EO, Meijer T, Vinyeta E, Vanderklis JD, Nielen MWF. Illegal Treatment of Barrows with Nandrolone Ester: Effect on Growth, Histology and Residue Levels in Urine and Hair. Food Addit Contam: Part A. 2012;29: 727-735.

13. Neves DBDJ, Caldas ED. GC-MS Quantitative Analysis of Black-Market Pharmaceutical Products Containing Anabolic Androgenic Steroids Seized by the Brazilian Federal Police. Forensic Sci Int. 2017; 275: 272-281.

14. Tricova B, Bosakova Z, Kozlik P. Development of an Ultra High-Performance Liquid Chromatography-Tandem Mass Spectrometry Method for the Determination of Anabolic Steroids Currently Available on the Black Market in the Czech Republic and Slovakia. Drug Test Anal. 2019; 11: 355-360.

15. Thuyne WV, Delbeke FT. Validation of a GC-MS Screening Method for Anabolizing Agents in Solid Nutritional Supplements. Biomed Chromatogr. 2004; 18: 155-159.

16. Odoardi S, Castrignano E, Martello S, Chiarotti M, Strano-Rossi S. Determination of Anabolic Agents in Dietary Supplements by Liquid Chromatography-High-Resolution Mass Spectrometry. Food Addit Contam: Part A .2015;32: 635-647. 
17. Minto CF, Howe C, Wishart S, Conway AJ, Handelsman DJ. Pharmacokinetics and Pharmacodynamics of Nandrolone Esters in Oil Vehicle: Effect of Ester, Injection Site and Injection Volume. J pharmacol Exp Ther. 1997; 281: 93-102.

18. Cavrini V, DiPietra AM, Raggi MA, Sarti R. Analysis of Nandrolone Esters in Oily Injections by Reversed-Phase High Performance Liquid Chromatography. $J$ Pharm Biomed Anal. 1987;5: 21-32.

19.Mukherjee J, Das A, Chakrabarty US, Sahoo BK, Dey G, Choudhry H, Pal TK. Development and Validation of RP-HPLC Method to Determine Nandrolone Phenylpropionate in Different Pharmaceutical Formulations. Acta Pol Pharm. 2011;68: 155-160.

20. Li Y, Yu P, Wang Q. Determination of Anabolic Hormones in Porcine Hair by High Performance Liquid Chromatography-Mass Spectrometry. Anal Lett. 2o16; 49: 2895-2906.

21.He L, Huang XH, Fang B, Huang S, Cao Y, Chen J, Zeng Z, Chen Z. Determination of Eleven Steroid Hormones in Animal Muscle Tissues and Eggs using Ultra-Performance Liquid Chromatography-Tandem Mass Spectrometry. Chin J Chromatgr. 2oo8; 26: 714-719.

22. ICH Harmonised Tripartite. Impurities in New Drug Substances.Guideline.20o6, Q3A(R2).

23. ICH Harmonised Tripartite. Stability Testing of New Drug Substances and Products. Guideline. 2003, Q1A (R2).

24. ICH Harmonised Tripartite. Photostability Testing of New Drug substances and Products. Guideline.1996, Q1B.

25. ICH Harmonised Tripartite. Validation of Analytical procedure: Text and Methodology. Guideline.2005, Q2(R1).

26. Blessy M, Patel RD, Prajapati PN, Agrawal YK. Development of Forced Degradation and Stability Indicating Studies of Drug-A Review. J Pharm Anal. 2014;4: 159-165. 